\title{
Strategic Modeling for the Characterization of the Conditions That Allow the Anticipation of the Consumer's Requests*
}

\author{
Carlos Alberto Fróes Lima1\#, Bernardo Marega Luz¹, Sílvia Tamada Takemoto, \\ Paulo Barisson Jr. ${ }^{2}$, Roberto Antônio Terencio Tezzin², Luciano E. A. Peres ${ }^{2}$, \\ Fabiana Nogueira Gamba M. dos Santos ${ }^{2}$, Tales Neves Anarelli², Andrea Florencio da Silva ${ }^{2}$ \\ ${ }^{1}$ R\&D Department, KNBS Telecomunicações e Informática Ltda., Campinas, Brazil \\ ${ }^{2}$ Customer's Relationship Department, CPFL Energia, Campinas, Brazil \\ Email: ${ }^{\text {froes@knbs.com.br }}$
}

Received 22 September 2015; accepted 23 October 2015; published 27 October 2015

Copyright (C) 2015 by authors and Scientific Research Publishing Inc.

This work is licensed under the Creative Commons Attribution International License (CC BY). http://creativecommons.org/licenses/by/4.0/

(c) (i) Open Access

\section{Abstract}

In order to recognize and anticipate customer's requests, reinforce and manage the communication and operational flows, analyses of which are the services that the consumers demand to the energy companies are extremely important. To improve each relationship channel and to recognize the customers' profile, expectations and needs, it has been necessary to reinforce the operational efficiency concerning costs and agility. Operational effectiveness answering the demands is pursued, considering the amount of services offered and generated by relationship channels, communication facilities and operational conditions provided by the companies. A huge amount of data had to be organized to represent this scenario and forecast the relationship. To represent it, models were created to monitor and predict customers' requirements based on historical and online data. There were established regional resources availability, weather conditions, problems concerning the energy distribution grid, as well as the motivation of the customers to use alternative medias or relationship channels. The big data treatment techniques were used in order to provide the necessary agility to achieve the monthly/hourly volume of data (millions of registers per month) and permit communication clusters' views.

\section{Keywords}

Customer' Attendance, Operational Improvement, Customer' Demands Anticipation, Relationship, Attendance Strategies

\footnotetext{
*Strategic modeling to improve the services and operation to energy industries' customers.

"Corresponding author.
} 


\section{Introduction}

The Brazilian energy sector and the distribution companies seek for the continuous improvement of the understanding about their relationship with their customers.

In Brazil, the distribution companies operate according to their federal concession areas and are responsible for delivering the energy to the customers' unities, which mainly belong to the regulated contracting environment. Even for the free market customers, the local distribution companies are responsible for the grid operation and maintenance, as well as the monthly billing of the delivered energy. To request for the energy companies' services, the customers have at their disposal different channels such as call centers, internet, social medias, e-mail, letters, SMS and personal attendance offices. The amount of executed services is a consequence of customers' needs for services, new connections to the grid, as well as related to power outage, billing and overdue debts.

The understanding of the reasons why the customers contact the companies is a result of the analysis of their personal necessities and of the regulated service conditions, as well as the grid operational situation, weather conditions and energy availability. The increase of attendance quality indicators affects straightly the operational costs, and vice versa. The lack of investments on the distribution grid or on some kinds of services increases the customers' demands.

The energy distribution companies continuously seek to assess the costs of the attendance process, find out new capabilities to address services and operational demands, and develop new systems and features in a strategic level to improve, maintain and track customers' satisfaction. CPFL Energy Company (with around 7.7 million customers), referenced in this work [1], located at Brazil Southeast region, continually looks for excellence and innovation in energy services, improves the relationship activities to allow prompt response to critical situations, new or already known demands.

In this respect, the knowledge and forecast of the customers' demands needs a view towards the asked and executed services, complemented by the measures and volume of data records at the relationship channels. Being so, the operational improvement of the relationship channels, concerning agility and costs, must be reinforced by the better knowledge of the customers and improved each time that they contact the companies or request for services.

Additionally, one unified vision of the volume and costs of the relationship for the entire company area may not truly represent the regional demands, which may be distinguished according to the specific characteristics, such as consumption profile, urban or rural areas characteristics and grid conditions. In this sense, a closer view by regions, cities or even neighborhoods could provide local better services and response. They will be able to direct their actions to reorganize operational teams and procedures, as well as personalize their services, attending seasonal and specifically customer profiles requirements.

Otherwise, the statistic models used for the analyses must be continuously revaluated and improved, according to the market dynamic, consumption habits, political and economic trends, as well as weather's technologies development and forecast. The defaulters have also been impacted by the social-economic scenario and represent relevant communication and costs to the company's attendance. As a rule, the defaulters are insecure regarding energy supply interruption and often and repeatedly seek services to restore the supply or to negotiate the debts. The system and models developed for this project considered this scenario, and must be continuously improved during the organization of the attendance process.

This evaluation points out variables to profile different aspects of the customers such as their energy consumption facilities, their commercial group behavior and also their financial registered records. The impact of these aspects or volume on the requested services and attendances was analyzed. This analysis is per si the main reason to quantify and qualify the strategies used by the companies.

To continuously improve the models, it also included analyses, concerning the customers' geographic positioning to identify the critical aspects of the regional relationship. Criticality models of attendance were developed according to criteria that could provide alerts and corrective measures efficiently. This analysis, that included the concepts of big data models organization, summarization analysis to accelerate the answers of the analytical systems to evaluate the relationships manners, was established and associated to the existent procedures. These procedures produced strategic and operational maps that updated and increased the current processes at the customers' relationship area, aggregating an environment that expanded the supervision of attendance conditions. 
There could be characterized methods to related regional aspects, kind of accomplished services, attendance medias or channels considering socio-economical aspects to cluster the customers and the attendances. As results, groups and business rules were generated, with statistic value to indicate the target medias that will provide better results for the relationship/actions with the customers of a specific region. The regional knowledge pointed out the areas that mostly demanded services and contacted the company, as well as the costs of the related services, improvement of the critical process concerning attendance, allowing the modernization of attendance structure and/or faster recognition of the problems or anticipation of the actions and results. Analytic tools were added to the evaluation routines by the company's channel and service control team.

The following items organize this development done focusing on customer communication. Item 2 highlights the current necessary communication improvements, item 3 followed with the methodological guidelines, item 4 the solution architecture and item 5 the results and benefits achieved. Item 6 shows up the system designed to represent the operational features to manage and forecast the communication, services records and relationships results.

These summarize up the knowledge organization focused on: i) the identification of conditions of customer attention; ii) the excellence of this attendance; iii) the situations and processes that can predict why the customers reach for the company and not only work to minimize or correct the problems. They achieve valuable information to cost-benefits analysis of the investments, for the continuous improvement and for the coordination of the attendance effectiveness.

\section{Development Motivation}

Many actions have been taken, in the energy sector, to achieve solutions for the customer attendance. However, few or none literature presents the problem of characterization and forecast of the relationship with the customers, based on their specific necessity, in the company's interactivity potential, medias or channel availability for attendance and the circumstances that trigger the energy customer demand for the company's attention.

This work intends to organize the issues related do relationship based on events recurrence analysis (power outrage, debts, energy supply interruption or other facts caused by the companies or by grid problems), customers' demands, evaluating the region/local attendance conditions, grid conditions, weather events and/or socialpolitical issues. By a systemic analysis of the regional attendance and clustering indicators, it was intended to estimate, detect, value and, if possible, predict the behavior and attendance necessities of the costumers when they contact the company. This communication view exposes the necessity and expectations that lead the costumers to demand a service and contact the company, as well as the effectiveness of the relationship.

This project pursued the balance of the relationship channel's point of view versus the services the customers ask for, to identify the customers' needs (as a methodologic model of complementary points of view). It encourages analyses of the costs, the effectiveness of the relationship channels and the services provided. It looks for better information records into the systems and characterization of the actions to relationship improvement by the channels (such as easier access to the services by the internet and call center, indicators for the improvement of the communication by Interactive Voice Response-IVR). The effectiveness of SMS usage to communicate energy supply rupture was followed by the generated software and validated. Better practices for the relationship were revisited, concerning the availability of the information for the customers and agility in answering them by the current attendance channels. Therefore, the methodologic process was integrated into the developed system.

The definition of the indicators and clusters was confirmed effective, mainly when associated to the concepts of critical volume of relationship generated by the amount of existing energy unities in each analyzed area. Therefore, a group of guiding situations was created among the developed tools, to ensure easier verification by the business analysts and their managers that had few or even none understanding of databases or information structure. A data warehouse was organized for the summarized treatment that allows the big data organization, as mentioned before.

The concepts of big data governance were tested, considering the necessary data quality management for consistent information extraction, without duplicity and following indicators rules. For the development, the various data company's sources (legacy systems and census information, primarily) were applied as they are the used to register the services asked by the customers. A new approach was structured to the services costs (considering the possibility of using different channels for the customer's relationship), also the system access optimization 
(responsiveness to the researchers/analysts responsible for the relationship channel and the company services managers).

A system was designed to organize the different situations related to the customer's attendance, the criticality of these situations and the regional representations of problems and solutions, applying analytical filters. The generated software CCAF-Contact Center Analytical Framework runs the historical patterns of the relationship between company and customer, which allows the analysts and managers to have systemic and specific attendances views. In this analysis, criticality maps, behaviors, services volume tendencies and customer profile filters, as well as payment done was provided by CCAF. It achieved up to the level of neighborhoods, so the analysts can have the monthly (to hourly) regional characterization of the services provided correlated to the installed energy customers there.

To ensure a convenient operation of historical research with the CCAF system, the big data techniques organization process were built, summarizing and consolidation data. The resulted system has capacity to process information of a 36 months basis of 7.5 million clients and 3.5 million attendances/monthly representing them on tendency graphics, strategic and criticality maps as well as services and channels performance indicators (allowing better results on technology, economy and efficiency for the historical researches). Additionally, detailed services consults were implemented and can be generated by the system for a deeper analysis of specific situations that may demand personalized actions by the company.

The customers' profiles that contact the company many times per month were established by the research in order to clarify which are their needs and their non-attended expectations that made them ask to service repeatedly. This was one of the paths towards the detection and prediction of effective solutions for the customers' relationship.

Additionally, this work sought the answers for performance and criticality by the attendance systems. It sought to provide conditions so that all customer segments can be analyzed and specific actions taken to an efficient operation:

- Costs - creating value for the company: different services provided by the channels were evaluated, qualifying and quantifying the attendance conditions on a historical basis, creating tendencies maps. Objective characterization of the services and channels' costs was applied, so that other possibilities, besides the current ones, could be analyzed. Better conditions for the web interface were proposed, in order to increase the customers' convenience and converge attention for systems with more effective operational costs;

- Support to the business departments: the CCAF system was conceived as a technical and administrative reference to understand the different services offered by channels in association with the services that are executed by the company's operational team. The losses and the debts management departments were considered during the process of association the current communication with the customers and the demands and the services tendencies generated;

- Services set: the customers' necessities were classified according to their specific profiles, related to the demanded services and a historical conditions provided;

- Regional problems and diagnosis with information about the commercial situations and historical demand. Considering the historical conditions and region, this system predict and evaluate to a neighborhood level the operational criticality, according to the customer's profile and demanded services at the attendance channels;

- Shorter response time: ensures a systemic evaluation, any time, by graphics, charts, maps and clusters attendance consults, provides agile analysis of the detected situations. Specific actions concerning the control of the demanded services are not considered in his project and may be relevant for a continuous process of analysis of the services and operational conditions demanded. These should be project next steps;

- New indicators consolidation: the CCAF system was based on performance indicators (volumes and costs) of the different channel, services and regions, with critical analysis based on the volume of the attendances related to the customers and clusters profiles. This model is convenient for the consolidation of the distributor effective conditions of interest, concerning its current analysis strategies of relationship and performance of its analysts. Other indicators can be incorporated with agility for an evolution of this model to represent the company's operation dynamism;

- Attendance medias and their costs, advantages and disadvantages: Comparisons among the different medias were presented and attempted to characterize the effectiveness of the channels based on historical behavior;

- Barriers: operational conditions were revisited, such as available data quality, monthly volume of data to be 
analyzed and attendants training conditions for specific procedures types, looking for the process robustness. Alerts were generated as a book of operational improvement, with actions that can ensure the correct register of the relationships requirements, complementary information that can become future indicators of attendance efficiency or services orders localization. Additionally a division between asked services at attendance channels and amount of operational demanded efforts to support them were reevaluated to effective measure the efforts taken for the attendance and for the operation;

- A system improving agility concerning actions at processes level, attendances, consolidated and emergencies scenarios: data load and integration within the operational space will enable the decisions taken closer to real time events. Considering the historical space as a reference, attention should be taken at daily/ hourly tendencies;

- Recurrent calls: the customers' services demanded records were analyzed. Therefore, the necessities presented by recurrent contacts can be continuously analyzed and specific actions taken in order to a better response to the customer or clusters to minimize the costs and the inadequate operational conditions;

- Which is the customer profile? Who are they? Why they contact the company? Which are the causes of their problems? The condition for the segregation built inside the system allows tracking for unusual customers' profile and regions demanded services. Specific conditions of the attendance were also evaluated as research models on analytic system basis, using market tools, by the company's specialist;

- Problem validation tree, by region and city: same as the above information plus thematic and criticality maps according to the region down to the neighborhood level;

- Call and recurrent calls reduction in the call center: this issue was analyzed considering the profile of the customers who often contact the company by the call center, focused on their region and debts payment. Proposals to improve the website/web portal were presented, in order to make the information easier for the customer and this as the preferred channel and not an alternative one. In addition, the effectiveness of this channel was questioned concerning the customers' wishes. The system was prepared to monitor the actions taken, to guarantee the visibility of the results and agility to indicate possible strategy corrections;

- Innovation: it was sought in all indicative elements linked to the system, since the granularity of neighborhood access to the clustering of customers' profile, channels and executed services. The analytic model for big data bases started may be replicated to the available analytical tools, improving the specialists' access to the detailed information of the historical relationships, strategic maps and attendance tendencies;

- Active and Reactive actions: the record accuracy of the actions resulting of the customers' demands was questioned to improve the relationship effectiveness and the provision of energy distribution services. Costs were analyzed and conditions of free attendance schedules were indicated (even with costs fixed by partners contract already established), demonstrating possibilities of operational proactivity, either considering the utilization of lower costs medias (website) or related to specific services;

- Databases effectiveness: some considerations were made throughout the project in order to improve the registers quality on the databases, via system and attendance process adjustments.

The starting was the historic quantitative calls/attendances. The indicators association KQI (Key Quality Indicator) results from proposed KPI (Key Performance Indicator) mapped here [1] [2]. At this moment, at the structural view were presented, the indicators were organized to help the identification of warning situations and tendencies, focused on the region granularity, monthly volumes and costs. The weekly, daily and real time operational views may be achieved since the mapping and organization of the process.

The companies need to identify the costs, the operational implications, the necessity of changing their systems to the relationship/communication demands, and add the possibilities and characteristics coming from the availability and costs differentiation resulted, searching for attendance excellence. These questions also reflect the employees of the distributors' necessities, demonstrating the breadth of modeling and implemented strategies.

Another important point to be emphasized is that this project is a part of the company's strategy in order to prepare new scenarios to smart grids and on the compromise with the customers relationship update. The next step will be the creation of new relationship environment that brings the convenience of the energy, products and correlated services usage. Insights must be offered to customers into how they use electricity and how they can actively manage their use, according to their priorities, comfort and costs. In this context, the distributors are in the best position to help their clients to manage the energy, and this is exactly what the customers wait for. This work starts this necessary visibility. 


\section{Methodologies}

The first chosen methodology was the CRISP-DM (Cross-Industry Standard Process for Data Mining) methodology as the guidance to the development because its characteristics concerning the organization of the data and its main principles: to motivate the tools inter-operation in data mining processing, demystify itand making the information treatment simple [3]-[6]. This organization was important to achieve a standard, structured and didactic procedure to the company's analysts, who will be responsible for the operational activities. This methodology provides:

- The project replicability;

- Support planning and management of projects;

- A "comfort/direction of how to do" for those who start in data mining knowledge;

- A formal structure (methodology) to record the experience about the mining, facilitating the business analysts team work;

- Decreases the dependence on great specialists;

- Motivates the best practices and helps to get better results.

The choice of this modeling methodology also supports the analytical tool used: SPSS Modeler [7]. The procedures were organized in the tool as a backbone, allowing and directing models and the construction of analytical solutions.

The attendance modeling in this project considered:

- Models used to segregate and quantify, on customers' historical consumption databases, arranged to improve the operation according to the consumption profile and regional or local characteristics (e.g. grid detected problems, defaulters, contact center attendance, attendances at the offices, etc.);

- Samples selection related to database records inconsistency;

- Analyses of defined variables correlation and indicators standardization;

- Consolidation of the collected information in indicators models;

- Statistical weights to clusters evaluation, determining variables to represent the region of the distributors area;

- Systems and of strategic changes for the relationship and communication improvement (process changes and attendance options propositions);

- Information management systems evaluation to show up the indicators defined and tuned to be useful, considering the amount of treated data;

- Characterization of the operational costs and assets to achieve the model;

- Characterization of the models and indicators settings to support the strategic application for the relationship, medias and services;

- Strategy for indicators exhibition, in a critical situations and troubleshooting consolidation system (historical and predictive).

The data preparation and the organization for the modeling demanded all the structure of big data characterization and governance rules [8] [9], by creating a set of indexes that allow access and categorization of the original data (raw, primary) and pre-compile consolidation done. Therefore, the knowledge basis was structured to be useful in two different ways:

- Graphic analysis basis to represent the tendencies of the customers' relationship necessities, allowing the visibility of the historical attendances in its best granularity. It intends to offer the vision of the attendance by each region of the company area, city and neighborhood, with segregation of the profile and consume classes, the understanding of the tendencies of the relationship channels and demanded services. There were added the payments conditions and the quantitative and regionalized characterization of recurrent calls, associated with customers' service expectation. A graphic visualization system was accomplished to represent the historical conditions and seasonality.

- Structured reference data warehouse to specific analysis and business conditions modeling useful to the company's analysts. It organizes the specific simulation conditions of attendance medias changes, costs, teams structure and support systems. It was developed to support the actions and models of tendency, applying analytic tools and providing specific activities for market intelligence.

In this sense, the services exploration and attendance resulted by specific channels can be motivated, increased or reduced with their operational costs adequacy. To do so, a detailed vision of relationship channels and 
services required in the various regions, cities or neighborhoods must be characterized (an example of the data organization is demonstrated in Figure 1). Therefore, the generation, monitoring and managing special campaigns, based on local reality may be more assertive concerning the customers' loyalty and meet their expectations.

With the presented structural vision, the indicators were organized to help the identification of alert situations and tendencies, focused on the regional granularity and customers' profile, concerning volumes and monthly, weekly, daily and on real time operational representation of relationship costs, volume and number of customers attended. The use of maps to represent the criticality/indicators results and alerts was modeled as demonstrated on Figure 2. The results can be seen in the map that represents cities criticality alerts at CPFL-Paulista's operational region (Figure 3), according to a selection of criteria based on the model presented on Figure 1.

\section{Solution Architecture}

Figure 4 shows the data flow in the service distributor process and organizes the understanding of the existing operation and the extraction condition from the database systems.

This vision consolidates an understanding about the data extraction for the proposed summarized data warehouse structure: a new organization consolidated on a structure of processing, using the attendances' primary data, as a backbone, aggregating customers' personal data registers, consumption, billing, payments and grid problems coming from the legacy systems. The data extraction periodicity will be established by the company according to its understanding of the historical process. The system had its modeling done for the near real-time processing, but the influences of the systematic extraction of the data, during the company operation time, will be defined according to the historical characterization or on line operation demand.

Consolidated data currently taken for analysis of the transaction by the company, were used at the beginning

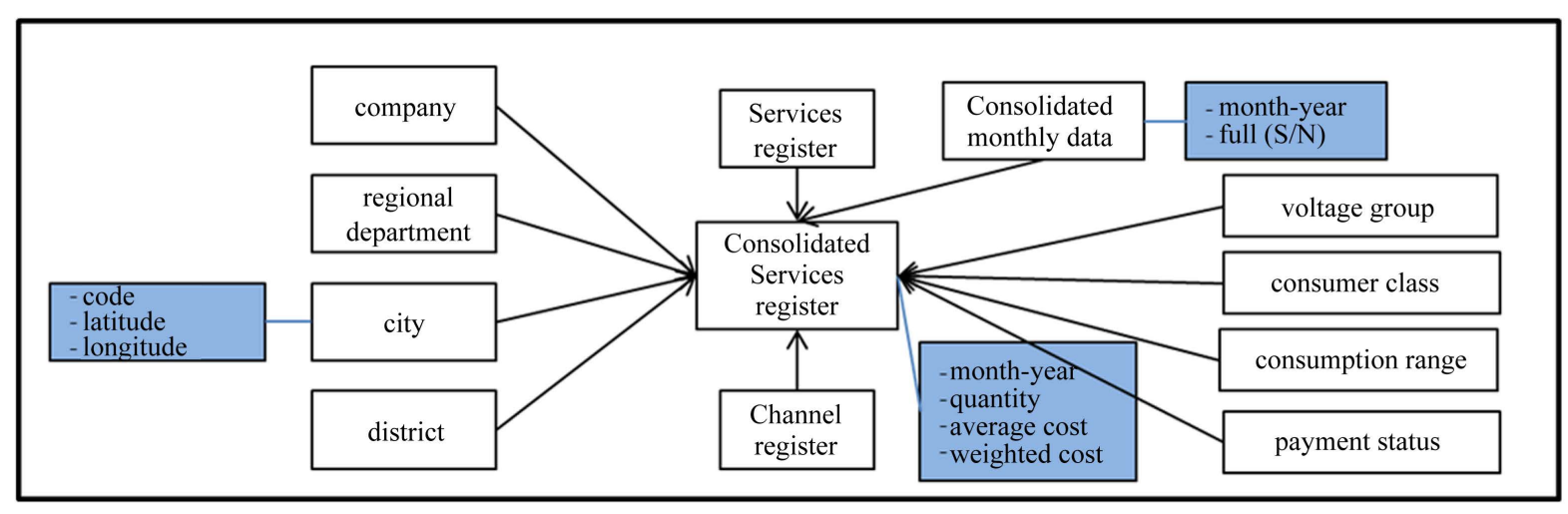

Figure 1. Consolidation for attendance registers organization.

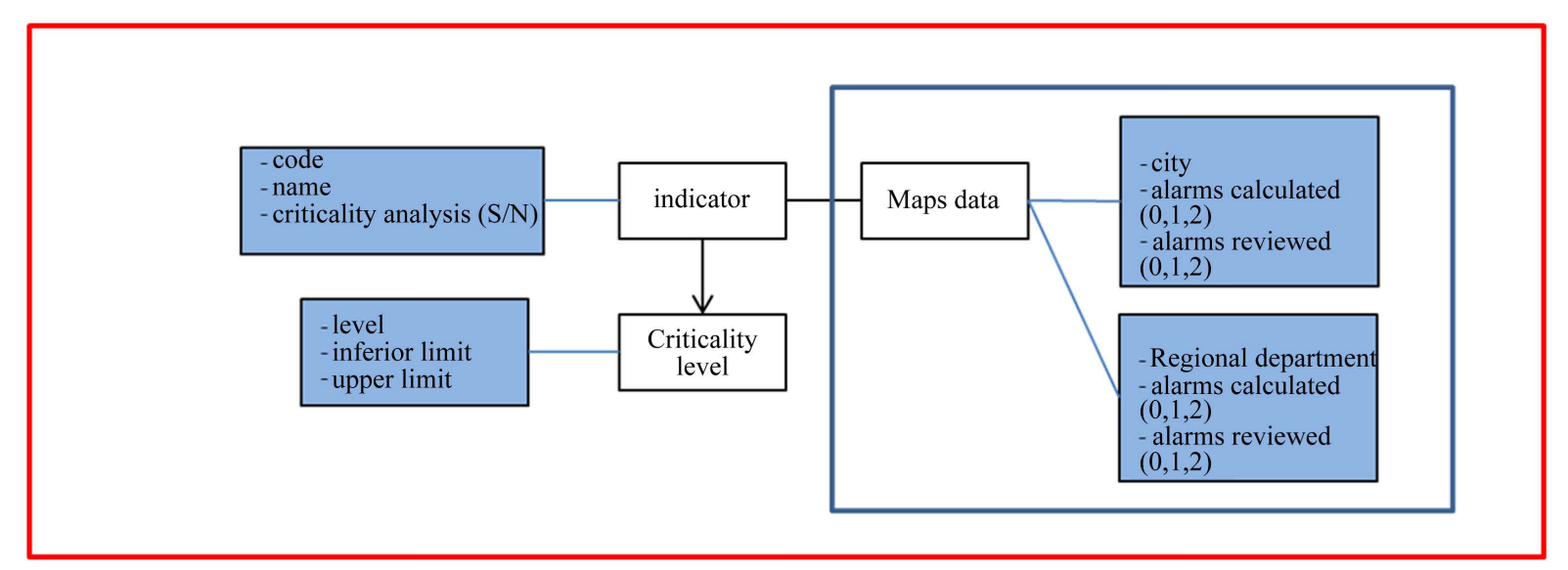

Figure 2. Indicators representation of the for the maps system. 


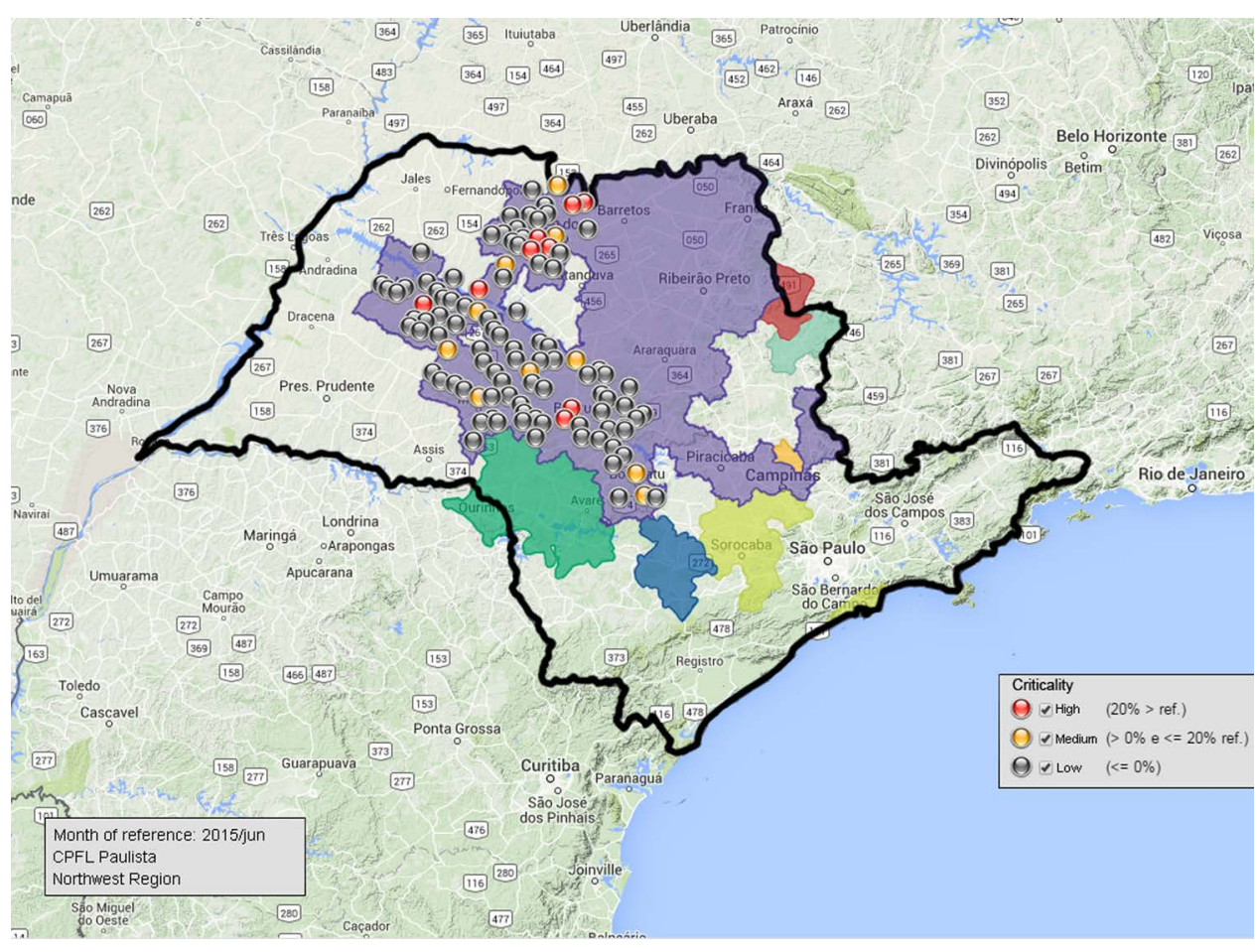

Figure 3. Northwest region of CPFL Paulista map, representing the criticality (alerts) regarding the cities number of customers x services required.

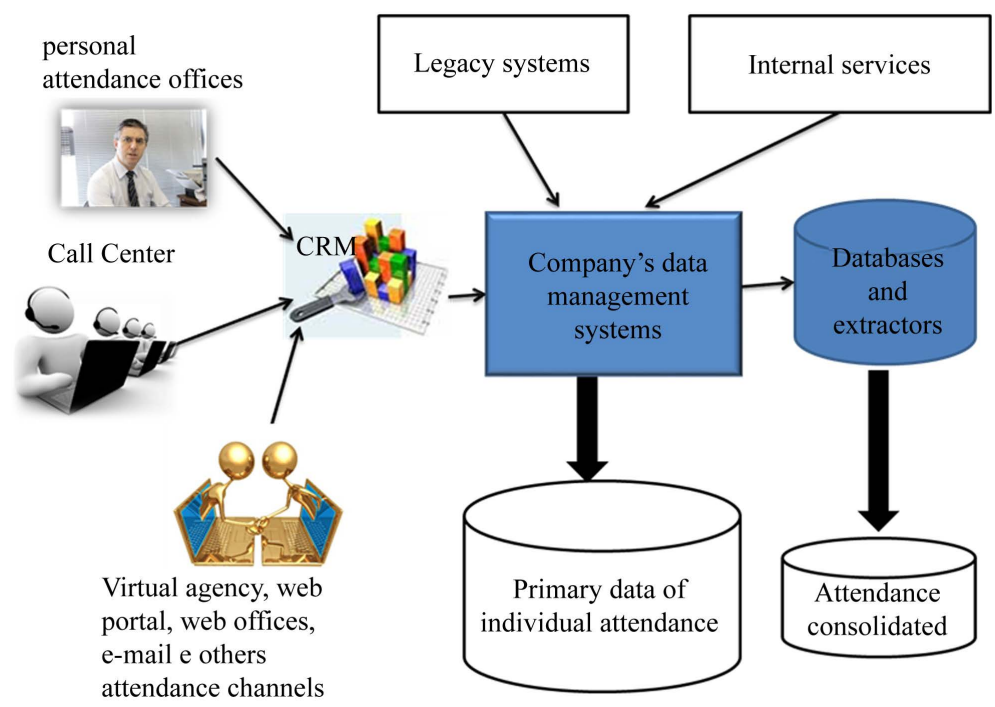

Figure 4. Distributor data processing flow.

of the activities as a way to confirm the developed analytical modeling. The processes currently used for the representation of monthly indicators could then be evaluated for maintenance or evaluated in its use.

It is worth reinforcing the conditions of organization and preparation needed in the primary data coming from different sources and that had to be consisted and validated before use.

The research needed to account for customer orders and their expectations of services, so that the choice of attendance channel could be the most effective for both (distributor and customer) from the standpoint of agility, accuracy and operational costs. So it was structured the accuracy of accounting data, information consolidation and recurrent services records associating them with the original design of monitoring. Operational improve- 
ment opportunities have been registered for the systems, services interfaces, and CRM, in the book of suggestions for improvement mentioned before, with proposals procedures and suggestions for evolution of systems, relationship platforms and attendance trainings.

\section{Results and Benefits}

The CCAF System allows analysis of use of service channels and services, facilitating correlations in demands for attendances with customers' profiles or requesting regions characteristics and providing support for decisionmaking. Many results can be obtained in the dynamics of relations operation, month by month, or in a period of observation. Some example situations are presented below, as proof of results for the operation and the customer relationship/communication. After the improvement, action implemented or changed processes, the system continues as a verification tool of the effectiveness of what was done:

- Situation example 1-Achieved result: improvement in customer interfaces on service portal. Sought for clarity and ease of use in this media, more direct answers to the customer needs and more adequate accounting access record. Valuation: from the service requested records at several channels it was detected weaknesses in accounting records by the consumer on the site, especially with regard to access to rebill service. It proposed an improved web portal interface, making it more robust. In addition, the site's usability was restudied due to customer navigability difficulties and responsiveness. Many times the customer, without correct answer at the web portal, looks for the services via call center to simple information, rebill account and/or to obtain a payment barcode. A change in this media (website) were proposed, using the concept of "one-click access” to obtain an objective way the information necessary for payment, including encouraging costumers to use the web portal to make their energy payments;

- Situation example 2- Achieved result: recognition of need for improvement processes to costumer request registers performed by call center, allowing their better accountability and appropriately qualification. Valuation: Were being recorded systematically requests made by the costumer as “general information” (unstructured services), when there were more appropriate services types for service requested identification. Some trainings performed and attendance proceedings reinforced allowed better information. Additionally, this allowed the evaluation of the needs presented by the requested services and prepare processes and specific attendance actions;

- Situation example 3-Achieved result: recognition of the effectiveness of the SMS channel as a warner of power disruption and repair time indicator. Valuation: the SMS deployment presupposes a customer satisfaction with information anticipation about grid failures. The monitoring of the actions taken could ensure better performance of the channel, procedures adjustments and warnings shipping reschedules;

- Situation example 4-Achieved result: attendance and service channels records costs structure revaluation. Valuation: considering the contractual structures and the processed amount of services by channel, there was time and resources availability to expand the responsive relationship. Therefore, were restudied each channel cost structures, redone planning service capabilities and analyzing various service contracts with partner companies. It sought to accomplish suitable operations for the occupancy of the attendance channel, offsetting any idleness with proactive and responsive relationship. Register update, e-mail billsand SMS notifications adhesion campaigns have been proposed to use these opportunities of resource availability;

- Situation Example 5- Achieved result: recognition of needed services by very demanding customers. Valuation: were characterized and studied situations of customers' multiple requests during the last 12 months. Searching robots were detected at web portal access. Additional security actions were implemented. Cases of not completed data records were also characterized as operational improvements to the CRM systems;

- Situation Example 6- - Achieved result: recognized plaintiff default costumer needs. Valuation: cases associating attendance request with power cut-off notices previously sent, because of default, generate excessive requests at different channels, mainly at call center. There are currently evaluating proposals for communication improvements for these default customers, taking precise information about procedures and times involved in the power cut-off and collection processes. It was also proposed changes at web portal, seeking usability and responsiveness in the case of late payments (complementing the situations presented in the situation Example 1);

- Situation Example 7- Achieved result: operational improvements proposed in case of delay of responses in the requests for change of contracts or reconnection. Valuation: characterize the amount of care and time to 
meet customer needs. Processes were restudied and sought operational agility.

- Situation Example 8-Achieved result: segmentation of relationship register between receptive and responsive. Valuation: for some relationship channels (mainly e-mails and correspondence) the legacy systems don't make the appropriated information record as receptive service (customer initiative) or responsive one (distributor initiative). Were proposed additional information record, relevant for resizing and prioritization of teams' structures, plus proper accounting of requests and answers.

- Situation Example 9-Achieved result: extension of consistency rules of activities records Valuation: It was identified what the CRM system register, eventually, two or more activities to the same user request. It has been suggested to improve the rules consistency across systems during the register of activities in order to eliminate such occurrences;

- Situation example 10 - Achieved result: providing new services and self-services facilities at web portal for the biggest clients. Valuation: simple service request detection, as rebills, consumption and payment historical information, at personal service channels, and more complex, as contractual changes done by e-mail or letters. For a complex service to the biggest clients, various activities need to be performed by analysts and take time to be fully completed. The availability of information and facilities at the website to complete and submit contracts, with cyber security and controlled document signings, improves the relationship sought. Others capabilities proposed solve noncomplex requests immediately;

- Situation Example 11- Achieved result: costumers' registers update to represent adequately their business activities. Valuation: there were identified probable errors or registration obsolescence that generated the application of consumption undue taxes. Customers were indicated to take their registers rechecked;

- Situation Example 12- Achieved result: notifications to managers and analysts with a critical regional attendance volume and excessive customers' requirements during an observation period. Warnings via SMS, e-mail and available on CCAF system. Valuation: It were characterized conditions and limits to establish critical levels for the attendances in the observation period;

- Situation Example 13- Achieved result: low-income population or low energy consumption pattern relationship characterization. Valuation: There were built social class profiles, using legal documents information provided by the customers, allowing appropriated segmentation of their requests and improving their relationships. Changes in intelligence were incorporated at IVR (Interactive Voice Relationship) for a closer service to these costumers;

- Situation Example 14- Achieved result: characterization of the attendances per day as a "heat map". Valuation: consolidation differentiated data service per day per customers' profile and region. This allowed an attendance quantitative and qualitative analysis and resource reorganization for seasonal and regional service provisioning (Figure 5).

These examples represent some of the initial detected operating conditions and capable of being monitored by analysts and managers at CCAF system. Other conditions and specificities are being used as a form of behavior

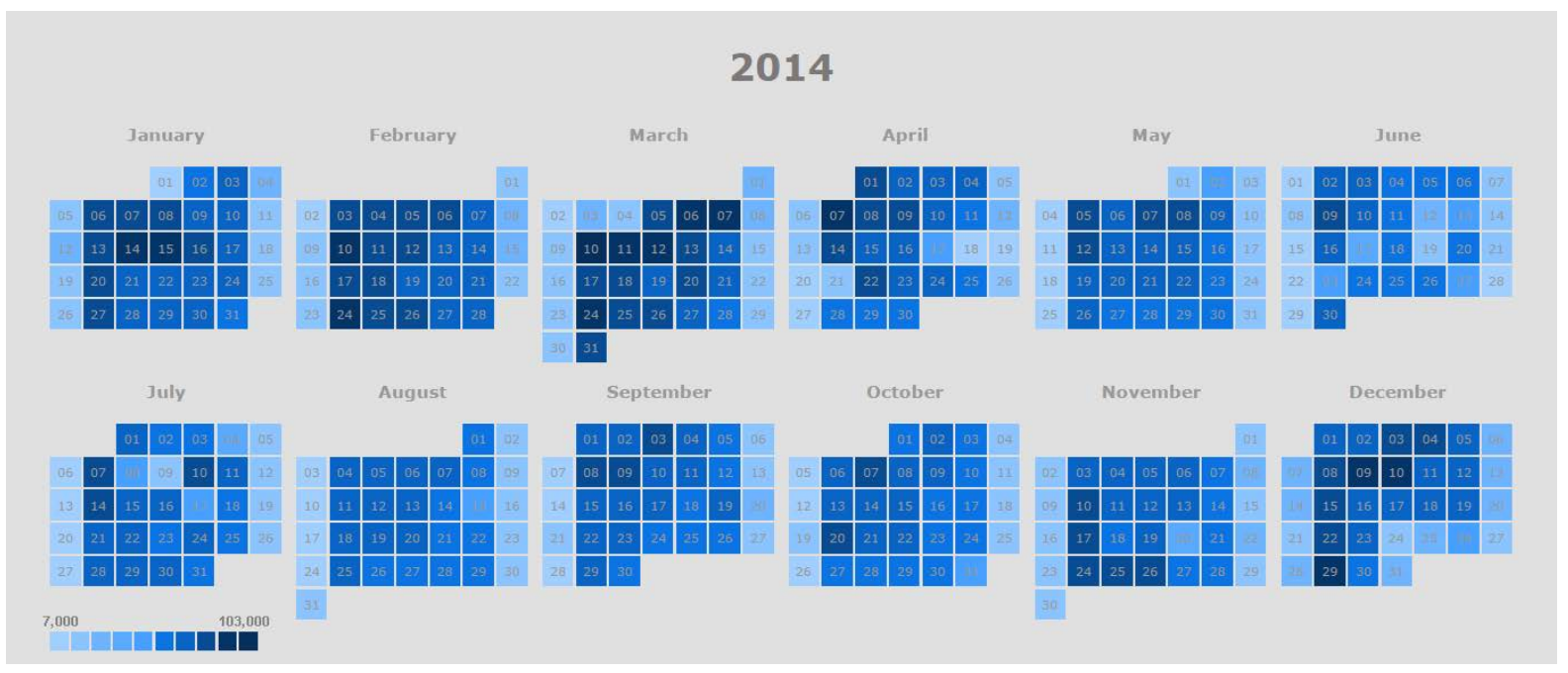

Figure 5. Map of amount of calls per day during 2014. 
analysis in this consolidated tool. Detailing or indicators associations as data mining process, using statistical and deterministic mechanisms are carried out via analytical tools SPSS Modeler [7].

This study sought to prepare the conditions for the treatment of large volumes of data and processes needed the information bases to support the relationship evolution trends that will come with the implementation of smart grids. In this new paradigm of network structures and control operation resources, new services and consumption detailed data information can be offered to customers. Systems, ways of access, control and organization of the communication should be exercised in a much broader way. The preparation of this relationship step must be done with the simplification of current attendances, in understanding of needs, available services and quantifying the resources involved (costs and response times). The demand for services to be performed not automatically should also be minimized, need for this constant systems upgrade to meet dynamic market requirements.

\section{The Information on CCAF System}

The CCAF system - Contact Center Analytical Framework-was developed as an historical trends system, allowing business analysts may build views with the depth of the relationship conditions and services requests made by customers. In the system, the interactions and the various service conditions can be viewed, including geospatial form (Figure 3).

In addition, specific conditions on service records in the distributor systems can be researched, thus allowing characterize and study situations and specific conditions of realized attendances, facilitating the analysis of the relationship held and allowing care requirements in future iterations. These situations are set out in specific queries available in the system screen panel (presenting services and costs organization).

An example of analyses in the system can be seen in Figure 6, with selection criteria: residential customers and consume range to the attendance channel web portal.

In December 2014, as a reference, $40.02 \%$ of the attendances made at web portal for the residential customers were originated from the distributor southeast region, which represents $33.80 \%$ of customers and $34.2 \%$ of all residential units. In the concession, in this same month, residential customers with consumption above 221 $\mathrm{kWh} /$ month, proportionally the number of units in the base, made more use of the web system than smaller costumers' consumption ranges. This behavior is justified by easier access to internet for the costumers with greater

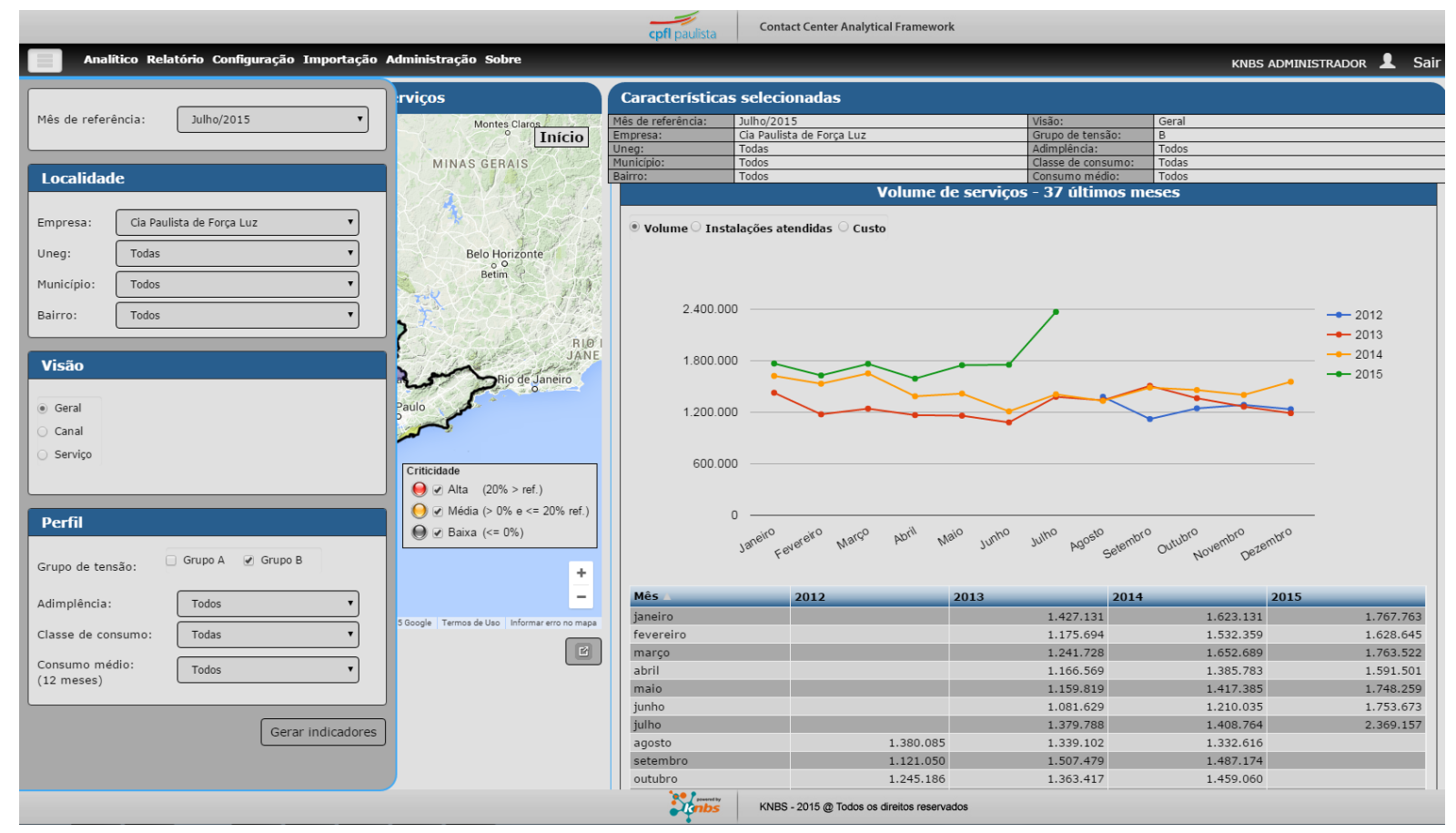

Figure 6. Residential costumer attendance at web portal channel. 
power energy consumption (possibly with better dwelling conditions, in general) -representing $29 \%$ of the residential customers and $36 \%$ of attendance by the channel.

In the distributor southeast region, the cities of Paulinia and Campinas, which represents about $45 \%$ of costumers, demanded about $54 \%$ of the attendances at the web portal. Thus, the campaigns on web portal for these cities will result far-reaching. In the mix of attendance channels in the referenced month, the web portal already has its visible representation, with growth trends (Figure 7).

From the amount of attendances to the residential customers, in December 2014, about 59\% represented attendances search related to debts and rebills, compared to $17 \%$ power disrupt notifications. From $62 \%$ of attendance requests by the residential customers related to debts, $36 \%$ are performed by web, $17 \%$ by call center and $9 \%$ at personal attendance offices (representing respectively 30\%, 5\% and 5\% of the services performed in December/2014 for these relationship channels). There is an inherent readiness facility of the Web response that should be strengthened. The annual trends view of attendance at personal attendance offices with their main services can be seen in Figure 8 extracted from the CCAF system.

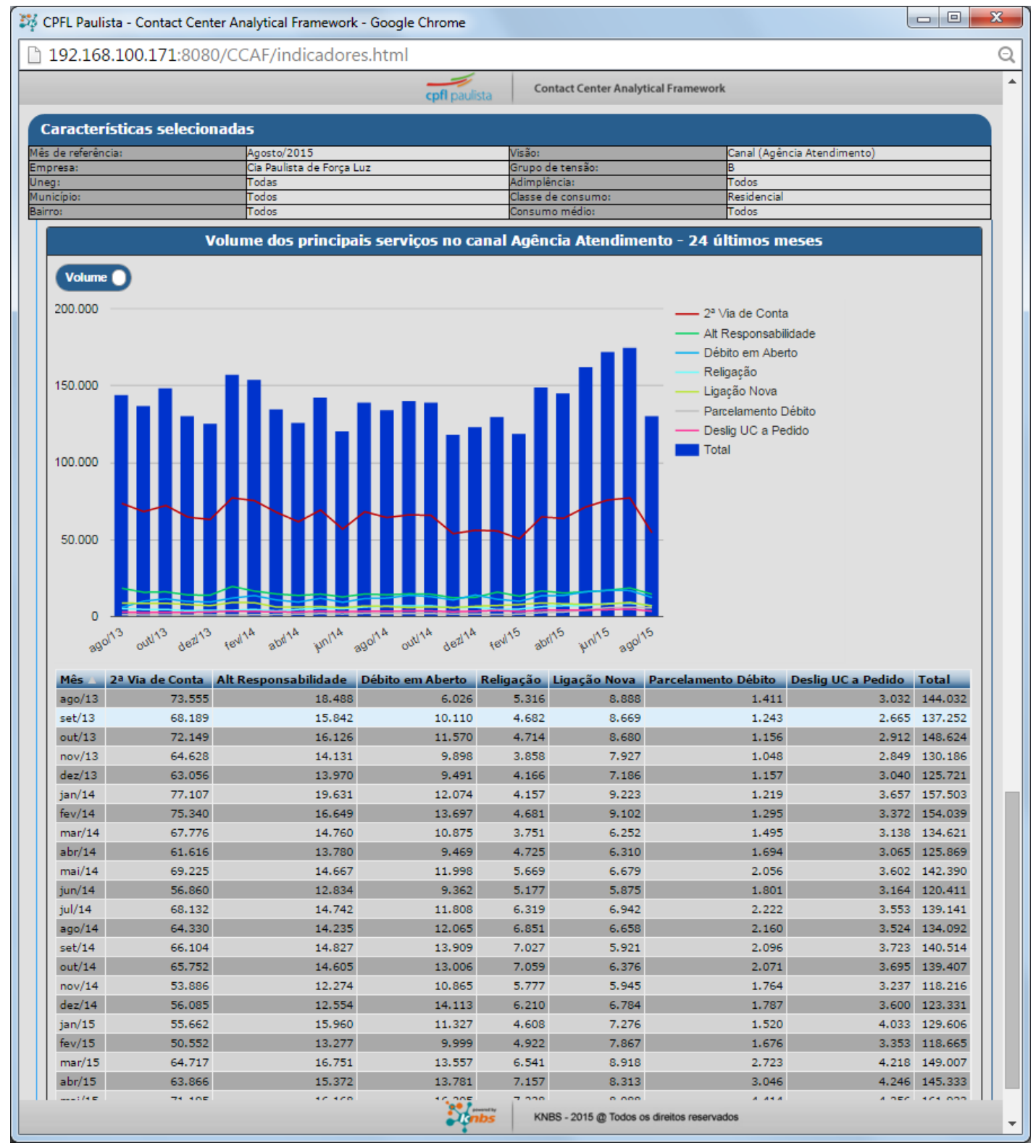

Figure 7. Attendance channels representativeness to the residential costumers. 


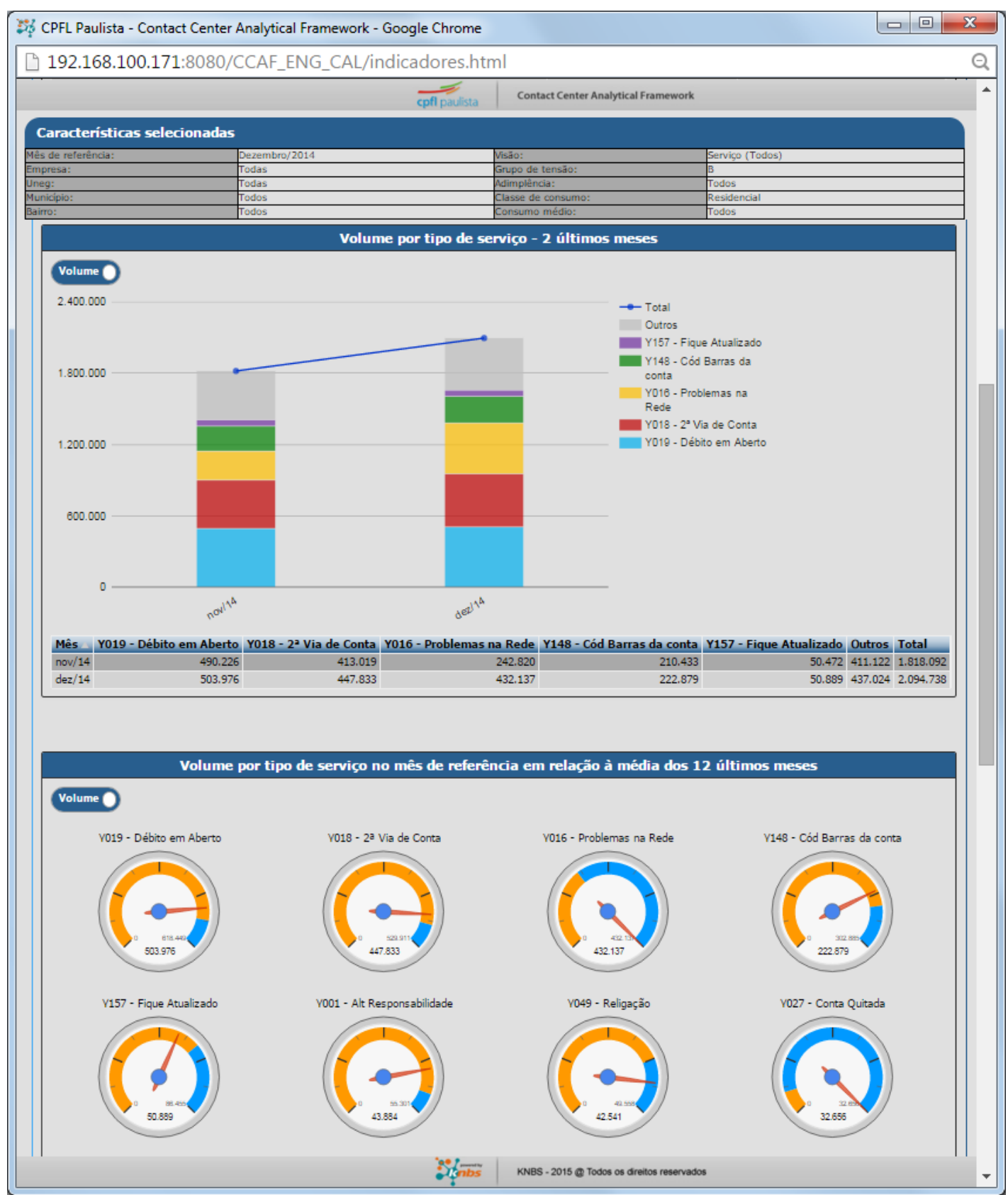

Figure 8. Register of performed services trends by residential customers at personal attendance officeschannel.

Some specific actions in internal processes of energy distributor have been taken to ensure a better result of attendance information recording. For instance, the existence of a generic service notification ("generic information to the customer") allows the operator register in a wrong way. An internal campaign and training were made and results could be checked in the services performed map. This record, in Figure 9, demonstrates the potential of the tool used to monitor actions taken by the distributor.

\section{Conclusions}

This work provided a new process to recognize customers as decision makers, choosers and hirers of services, preparing paths to the new relationship, now arising with energy companies' smart grid. It retries the product/ new services management on the network and differentiates communication with these buyers and their needs. 


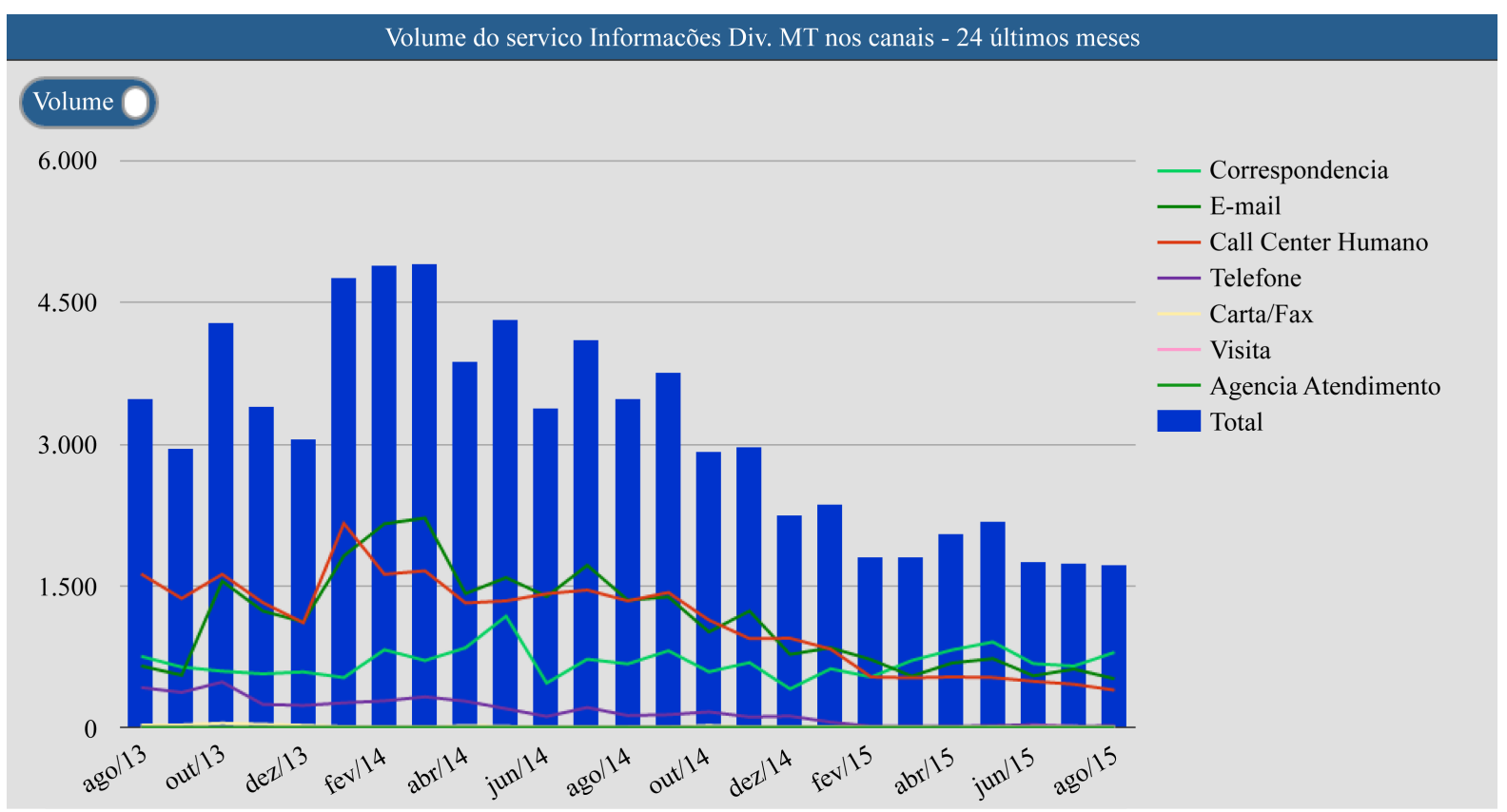

Figure 9. Service decrease trend after distributor internal campaign.

It was attempted to restructure the model of service conditions care and provision which suited to (or pointed out) the customers' specific needs and regional characteristics. From the viewpoint of operation, the recognition of the requested services in each attendance channel and improvement of knowledge of costumers/consumers expectations do or will do the difference to the relationship. The activities of analyses performed have contributed to improving friendly systems, as well as register and accounting of the customer requests with greater accuracy.

The indicators association (KQI), started at the operation dynamic, complemented the results of KPI mapping that were based on the regional attendance demand and costs. Additional indicators were organized to assist in the identification of alert and trend situations, focused on the regional granularity (cities and neighborhoods views) and in the customer profiles (consumer class according to the Brazilian regulation, consumption or energy tension range and bill payment). The historic trend analyses to attendances amounts and costs were built based on monthly services required. To the operation dynamics, the weekly, daily and real time views might be obtained from the process settled based on data input.

These new resources are now available to the business intelligence analysts to understand customers' relationships. The focus of initial activities was the evaluations of the unattended expectations presented by costumers that made multiple calls to solve their problems and the reinforcement to the defaults cases. These problems are recurrent and costly to the dealership, so special attention has been paid to the status of the customers' timely payment, registers effectiveness and the energy company's performance related to the requested services. The variables that represent the relationships are correlated with the performed services, regions and weather conditions to improve the knowledge of the common profiles and demanded services or stimulated by company campaigns.

From the viewpoint of grid weakness related to weather problems and grid failures, other evaluations are being generated, recognizing the biggest demand regions and trends, sending SMS to alert about unavailability and remaining time to service returns. This analysis and its efficiency are evidenced in the system features.

In this moment, the distributor is revaluating the costs variables ensuring more visibility and financial accuracy to the operation efficiency conditions.

It is important to emphasize the uniqueness of analyses, considering the indicators' visibility and granularity, to represent the communication with the customers and relationship conditions considering the regions, cities, neighborhoods that present specific needs.

The smart grid future demands and services offers must pass by this way, trading big data associations at distributor data bases, providing support to new business opportunities and efficiency at critical operation times. 
The next steps are directly related to the dynamics of operational and customers' communicational needs. The first step that will be taken is to generate an open organizational model of the relationship effectiveness.

\section{Acknowledgements}

The team of the distributor CPFL Paulista responsible for the customer service processes has the great merit of seeking renew dynamics of actions and procedures across the new technological possibilities.

This allows them to devote time to customer recognition, non-compliance service conditions and the constant evolution about their organization technique knowledge aimed to productivity and business intelligence. This should be recognized on the proposed changes with this work, which rearranges an operational culture status, modifies and expands the way of decision-making. KNBS built conditions that were accepted by the distributor that will allow higher flights with the new challenges that will come with smart grid technologies, new and clear services, the new costumers' position in the process, who will have more power of decision about the services offered and their loyalty.

The preparation of this renovation environment for the area, with new communication guidelines on an operating model based on indicators, was very fruitful. The whole team should be congratulated for their contributions and guidelines for the result achieved.

\section{References}

[1] Parmenter, D. (2007) Key Performance Indicators: Developing, Implementing and Using Winning KPIs. John Wiley \& Sons, Inc., Hoboken, 236 p.

[2] Alexander, J. (2006) Performance Dashboards and Analysis for Value Creation. Wiley, Hoboken.

[3] Chapman, P., Clinton, J., Kerber, R., Khabaza, T., Reinartz, T., Shearer, C. and Wirth, R. (2000) CRISP-DM 1.0 Step-by-Step Data Mining Guide. https://the-modeling-agency.com/crisp-dm.pdf

[4] Shearer, C. (2000) The CRISP-DM Model: The New Blueprint for Data Mining. Journal of Data Warehousing, 5, 13-22.

[5] Clifton, C. (2004) Introduction to Data Mining. Purdue University, West Lafayette. http://www.cs.purdue.edu/homes/clifton/cs490d/Process.ppt

[6] Li, Y. (2004) CRISP-DM. http://paginas.fe.up.pt/ ec/files_0405/slides/02\%20CRISP.pdf

[7] IBM SPSS Modeler CRISP-DM Guide. ftp://public.dhe.ibm.com/software/analytics/spss/documentation/modeler/14.2/en/CRISP_DM.pdf

[8] Sathi, A. (2013) Big Data Analytics, Disruptive Technologies for Changing the Game. 2nd Edition, MC Press Online, 73 p.

[9] Soares, S. (2012) Big Data Governance-An Emerging Imperative. MC Press Online, 342 p. 